\title{
Study of the Power Grid Enterprise Performance Based on Data Envelopment Analysis
}

\author{
Shuguo Zhang \\ ${ }^{1}$ North China Electric Power University/Department of \\ Economic Management, \\ Baoding,Hebei 071000,China
}

ABSTRACT - In this paper, data envelopment technology is applied to estimate the comprehensive technical efficiency of power grid enterprises and study its pure technical efficiency and scale efficiency. The calculation result is analyzed. Through the analysis of the actual operation results of the input redundancy and output deficiency, this result is associated with the local GNP data. The reasonable value of the input and output of the power grid enterprises to achieve the best performance is obtained by the prediction of the future local GNP values.

KEYWORD- DEA, power grid enterprises, investment a nd outcome

\section{INTRODUCTION}

With the promulgation of the new electric power reform policy, the highlight is that the grid has a clear positioning. Grid is a high-speed channel of the electricity transmission. Grid is no longer to get the difference of internet and the sale price as the main source of income, but to charge the crossing fee in accordance with the approved by the government of the transmission and distribution price ${ }^{[1]}$.Net service fee is unified by the state, so if the power grid companies want to further profit it needs to find new revenue points such as improving the quality of brand services, reducing operating costs and the damaging of network equipment.

\author{
Jingjie Niu \\ ${ }^{2}$ North China Electric Power University/Department of \\ Economic Management, \\ Baoding,Hebei 071000,China
}

Policy has increased the new five category of electricity sales and broken the situation that the grid is the only company which can direct purchasing electricity from power generation enterprises ${ }^{[2]}$.Power grid enterprises were striped out from the traditional link, forming a commercial operation of the enterprise. So it is necessary to improve the performance level of the power grid enterprise and enhance its core competitiveness in the whole system ${ }^{[3]}$.In this paper, the efficiency of twelve power supply companies in a certain region is analyzed by using data envelopment analysis, and the improvement measures are put forward. Innovation point lies in the final analysis result in contact with the local GNP. By analyzing the relationship of least input and largest output and the local gross national product it is put forward that according to the predicted local GNP decides the minimizing input and the maximum output to obtain the best performance of power grid enterprise.

\section{Data Envelopment Analysis Model}

Data envelopment analysis (DEA) is a linear programming methodology for evaluating the relati ve technical efficiency for each member of a set o $\mathrm{f}$ peer decision making units (DMUs) with multipl e inputs and multiple outputs ${ }^{[4]}$.Technical efficiency refers to the extent to which the production proce ss of a production unit reaches the technical level of the industry and is measured by input and outp $u t^{[5]}$.Technical efficiency is measured by the extent of the maximum output when the input has been 
determined. When output has been established, tec hnical efficiency is measured by the extent of the minimize input.

\subsection{The CCR Model of Constant Return to} Scale

The CCR model assumes that the scale efficiency is constant, and the technical efficiency is included in the scale efficiency ${ }^{[6]}$, so it is called the comprehensive technical efficiency.CRS=VRS*Scale Efficiency.

The paper supposes that the number of technical efficiency of DMU is $\mathrm{n}$ denoted by $D M U_{j}(j=1,2, \cdots, n)$.Each DMU has m different kinds of inputs denoted by $x_{i}=(i=1, i=2, \cdots, m)$. The weights of inputs are expressed as $v_{i}(i=1,2, \cdots, m)^{[7]}$. The number of outputs is q denoted by $y_{r}(r=1,2, \cdots, q)$. The weight of output is expressed as $u_{r}(r=1,2, \cdots, q) . D M U_{k}$ is being measured.

Linear programming model is as follows:

$$
\begin{aligned}
& \max \sum_{r=1}^{q} u_{r} y_{r k} \\
& \text { s.t. } \sum_{r=1}^{q} u_{r} y_{r j}-\sum_{i=1}^{m} v_{i} x_{i j} \leq 0 \\
& \sum_{i=1}^{m} v_{i} x_{i k}=1 \\
& v \geq 0 ; u \geq 0 ; i=1,2, \cdots, m ; r=1,2, \cdots, q ; j=1,2, \cdots, n
\end{aligned}
$$

\subsection{BCC Model of Variable Return to Scale}

The BBC model is based on variable return to scale and technical efficiency excludes the influence of scale ${ }^{[8]}$. So it is called pure technical efficiency PTE. $\min \theta$

$$
\begin{aligned}
& \text { s.t. } \sum_{j=1}^{\mathrm{n}} \lambda_{\mathrm{j}} x_{i j} \leq \theta x_{i k} \\
& \sum_{j=1}^{n} \lambda_{\mathrm{j}} y_{r j} \geq y_{r k} \\
& \sum_{j=1}^{n} \lambda_{j}=1 \\
& \lambda \geq 0 ; i=1,2, \cdots, \quad m ; \quad r=1,2, \cdots, q ; j=1,2, \cdots, \quad n
\end{aligned}
$$

\subsection{The Adjustment of Input And Output}

Through the analysis of the relative efficiency situation of each decision-making unit, it finds ou $t$ the ineffective DMU ${ }^{[9]}$. The improving value of $i$ nvestment is represented by negative numbers and the improving value of the output is represented $\mathrm{w}$ ith positive numbers. Therefore, the calculation met hod of the input and output projection value of $\mathrm{D}$ MU can be expressed as Target = original value + improvement, Strong effective target $=$ original va lue + proportional improvement value + relaxation improvement, Weak effective improved value $=$ ori ginal value + ratio improvement ${ }^{[10]}$.In this paper, selection of modifier is the second strong target ef fectively.

According to the modifier can obtain input an $\mathrm{d}$ output values which make the power grid enterp rises to the best performance ${ }^{[11]}$. In this paper, th ese values are linked to the gross national product. The next year power grid enterprises can choose the best of input or output values according to the predicted local national gross national product $(\mathrm{G}$ $\mathrm{NP})$.

3.The Application of Data Envelope in Power Grid Enterprises

\subsection{Basic Data}

According to the previous references and the characteristics of the power grid enterprises, three input indicators and two output indicators are selected 
including the substation capacity below of $110 \mathrm{kV}$, cost of power supply, the length of transmission line, electricity sales, the number of customers. The local national product is considered as a reference indicator.

Table 1:Data of twelve electric power companies in a certain area

\begin{tabular}{|l|l|l|l|l|l|l|}
\hline DMU & $\begin{array}{l}\text { Substation } \\
\text { Capacity Below of } \\
10 \mathrm{kV}(100 \mathrm{MVA})\end{array}$ & $\begin{array}{l}\text { Cost of Power } \\
\text { Supply(Million })\end{array}$ & $\begin{array}{l}\text { The Length of } \\
\text { Transmission } \\
\text { Line(Kilometer) }\end{array}$ & $\begin{array}{l}\text { Electricity } \\
\text { Sales(100MWh) }\end{array}$ & $\begin{array}{l}\text { The Number of } \\
\text { Customers(Ten Thousand) }\end{array}$ & GNP(Billion) \\
\hline 1 & 103.02 & 129.41 & 448.7 & 102.8 & 69.78 & 242 \\
\hline 2 & 177.76 & 179.48 & 1542.3 & 249.8 & 86.25 & 161 \\
\hline 3 & 153.85 & 186.64 & 2142.72 & 211.9 & 140.28 & 215 \\
\hline 4 & 177.56 & 165.23 & 1265.48 & 344.8 & 120.88 & 340 \\
\hline 5 & 102.84 & 152.6 & 2124.95 & 183.1 & 67.38 & 82 \\
\hline 6 & 97.38 & 168.42 & 3285.78 & 127.8 & 109.54 & 101 \\
\hline 7 & 113.3 & 215.21 & 3094.22 & 220.5 & 79.18 & 89 \\
\hline 8 & 100.23 & 182.35 & 2943.93 & 128.7 & 162.03 & 181 \\
\hline 9 & 214.26 & 226 & 2690.37 & 172.9 & 150.23 & 280 \\
\hline 10 & 80.24 & 172.46 & 2733.71 & 105.7 & 223.99 & 112 \\
\hline 11 & 48.759 & 76.97 & 1316.1 & 78.7 & 51.36 & 69 \\
\hline 12 & 47.11 & 103.27 & 1433.78 & 115.1 & 126.55 & 134 \\
\hline
\end{tabular}

\subsection{The Calculation Results}

In this paper, according to the characteristics of the power grid enterprise itself wants to use fewer inputs to get the corresponding output. Therefore, the paper uses input-oriented DEA model to calculate the input-output efficiency of each power company and use the CCR model to calculate the comprehensive efficiency of decision making units. The BCC model is used to evaluate the pure technical efficiency and scale efficiency of decision making units. These theories are used to get the comprehensive technical efficiency, pure technical efficiency and scale efficiency value shown in the following table. 
Table 2:Scale efficiency

\begin{tabular}{|l|l|l|l|l|}
\hline DMU & $\begin{array}{l}\text { Technical Efficiency } \\
\text { Score(CRS) }\end{array}$ & $\begin{array}{l}\text { Pure Technical Efficiency } \\
\text { Score(VRS) }\end{array}$ & Scale Efficiency Score & RTS \\
\hline 01 & 1 & 1 & 1 & Constant \\
\hline 02 & 0.712128 & 0.771791 & 0.922696 & Increasing \\
\hline 03 & 0.741412 & 0.756933 & 0.979494 & Decreasing \\
\hline 04 & 1 & 1 & 1 & Constant \\
\hline 05 & 0.823563 & 0.833565 & 0.988 & Decreasing \\
\hline 06 & 0.580946 & 0.612017 & 0.949231 & Increasing \\
\hline 07 & 0.836242 & 0.943963 & 0.885885 & Decreasing \\
\hline 08 & 0.714309 & 0.731361 & 0.976686 & Decreasing \\
\hline 09 & 0.614736 & 0.634082 & 0.96949 & Decreasing \\
\hline 10 & 1 & 1 & 1 & Constant \\
\hline 11 & 0.733828 & 1 & 0.733828 & Increasing \\
\hline 12 & 1 & 1 & 1 & Constant \\
\hline
\end{tabular}

It can be seen from the above that four powe $r$ company as the DEA is relatively effective. Com pany is better in general. For other two power sup ply company scale efficiency is higher $(>0.8)$.The 1 ower comprehensive efficiency of 11th companies was caused by the lower scale efficiency. The othe $r$ five companies mainly because of lower pure tec hnical efficiency, in turn, affects the overall efficie ncy. In the later business, these companies pay att ention to the improvement of technical efficiency. There are five companies in the decreasing returns to scale. They Should narrow the scale of produc tion and reduce inputs. And there are three compa nies in increasing returns to scale. Therefore, these companies Should expand the scale of production and increase inputs.

For inefficient companies we need to analyze the degree of redundancy and adjust its input and output values, so that it reaches the relative efficie ncy. The analysis of redundancy is shown in the $f$ ollowing table. 
Table 3:Data after adjusting

\begin{tabular}{|l|l|l|l|l|l|l|}
\hline & & $\begin{array}{l}\text { Substation } \\
\text { Capacity Below } \\
\text { of } \\
\text { DMU }\end{array}$ & $\begin{array}{l}\text { Sost of Power } \\
\text { Supply(Million })\end{array}$ & $\begin{array}{l}\text { The Length of } \\
\text { Transmission } \\
\text { Line(Kilometer) }\end{array}$ & $\begin{array}{l}\text { Electricity } \\
\text { Sales(100MWh) }\end{array}$ & $\begin{array}{l}\text { The Number of } \\
\text { Customers(Ten Thousand) }\end{array}$ \\
\hline 1 & $110 \mathrm{kV}(100 \mathrm{MVA})$ & 129.410 & 448.700 & 102.8 & 69.780 \\
\hline 2 & 0.712128 & 126.586 & 127.814 & 1087.255 & 249.8 & 102.102 \\
\hline 3 & 0.741412 & 99.805 & 138.379 & 1551.980 & 211.9 & 140.280 \\
\hline 4 & 1 & 177.557 & 165.230 & 1265.480 & 344.8 & 120.880 \\
\hline 5 & 0.823563 & 84.695 & 125.681 & 1469.483 & 183.1 & 132.161 \\
\hline 6 & 0.580946 & 56.555 & 97.846 & 1238.463 & 127.8 & 110.382 \\
\hline 7 & 0.836242 & 94.755 & 179.982 & 2371.413 & 220.5 & 210.446 \\
\hline 8 & 0.714309 & 59.715 & 130.257 & 1873.082 & 128.7 & 162.030 \\
\hline 9 & 0.614736 & 81.808 & 138.936 & 1653.930 & 172.9 & 150.230 \\
\hline 10 & 1 & 80.242 & 172.460 & 2733.710 & 105.7 & 223.990 \\
\hline 11 & 0.733828 & 35.781 & 56.484 & 683.394 & 78.7 & 61.219 \\
\hline 12 & 1 & 47.105 & 103.270 & 1433.780 & 115.1 & 126.550 \\
\hline
\end{tabular}

According to the above adjusted data and the local gross national product (GNP) as the reference data predicts that electric power company in the same output has minimum inputs and in the same input amounts may obtain the maximum output in the future. The curve can be made including the local gross national product and the best investment and output.
And when the gross national product (GNP) is forecast between $69 \sim 340$ billion through this point makes the straight line paralleling to the vertical axis. The intersection point of the straight line with other line is the optimal value of the input and output. The line chart is shown in the below. 


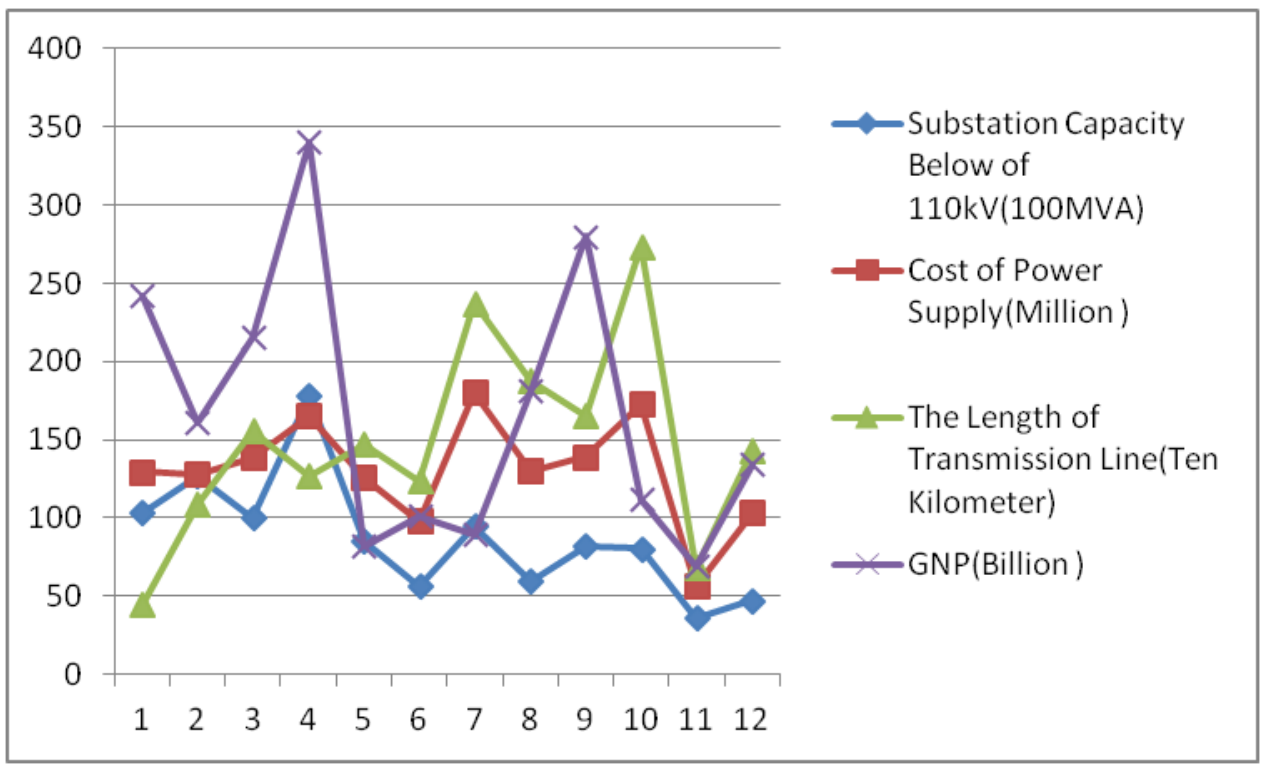

Figure1 GNP and inputs diagram

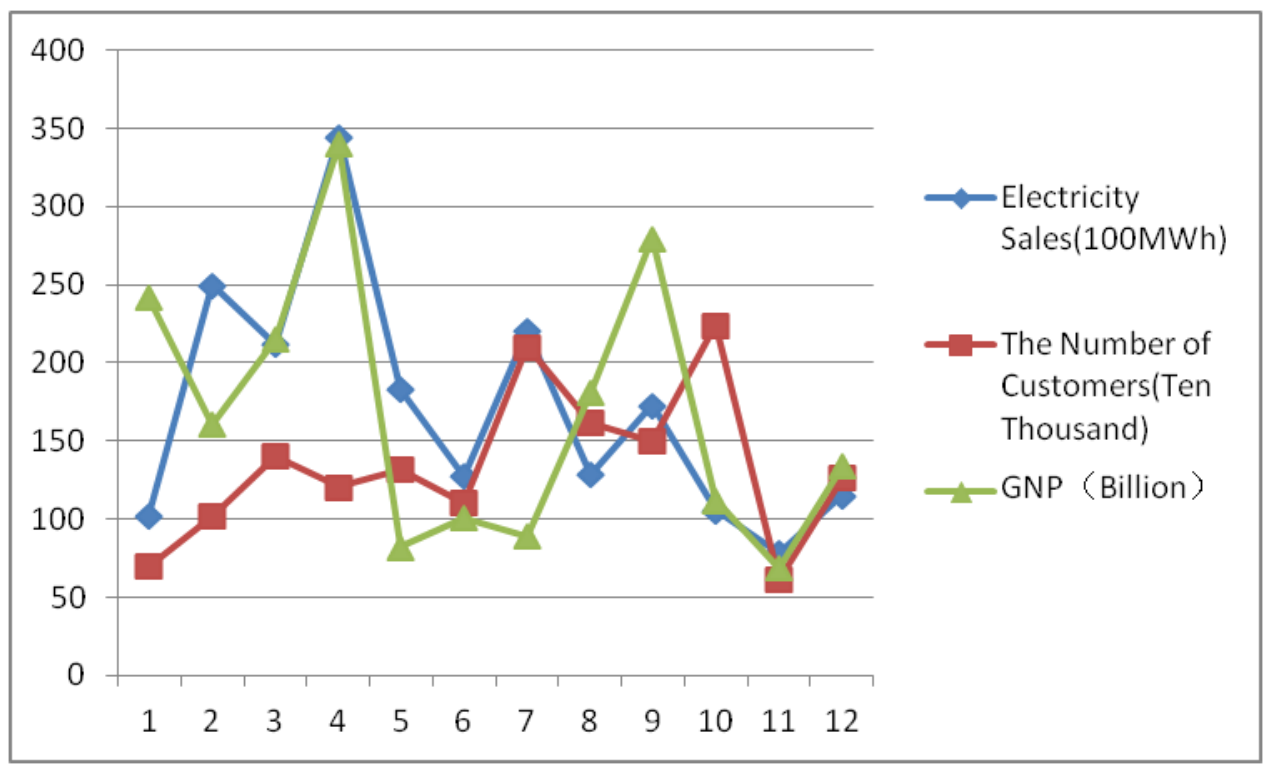

Figure2 GNP and output factor diagram

\section{Conclusion}

In this paper, the CCR and BCC model of the input oriented data envelopment analysis is carried out to analyze the comprehensive technical efficiency, pure technical efficiency and scale efficiency of 12 power enterprises. Improvement opinions are put forward. The redundancy analysis for 12 power companies show the best production and output which is associated with the local GDP. And then, when the gross national product is predicted to be in a given range, the best input and output can be obtained according to the line chart. 


\section{References}

[1] Manping Liu, Core, Focus and influence of the new power reform program [J], Macroeconomic Management, 2015, 06: 20-22.

[2] Gang Cheng, Data envelopment analysis methods and maxDEA software [M], Beijing: Intellectual Property Right Press, 2014.

[3] Ting Hu, Study on the input-output performance evaluation of power grid enterprise based [J], Management Observer, 2014, 23: 88-91.

[4] Lei Huang, Study on electricity distribution performance evaluation based on data envelopment analysis [D], Chongqing University, 2007.

[5] Narvendra Singh Chauhan, Pratap K.J. Mohapatra and Keshaw Prasad Pandey, Improving energy productivity in paddy production through benchmarking-An application of data envelopment analysis [J], Energy Conversion Management, 2006,47:1063-1085.

[6] William Wager Cooper, Lawrence M. Seiford and Joe Zhu, Handbook on data envelopment analysis[J],
Boston: Kluwer Academic Publisher, 2004, 1-39.

[7] T.Kuosmanen and M. Kortelainen, Measuring eco-efficiency of production with data envelopment analysis [J], Journal of Industrial Ecology, 2005, 9: 59-72.

[8] Cooper WW, Seiford LM and Tone K, Data envelopment analysis: a comprehensive text with models, applications, references and DEA-solver software [J], New York: Springer, 2007.

[9] Teng Fei and Wu Zongxin, Performance analysis of China electric power enterprises[J], Quantitative and Technical Economics Research, 2003, 06: 127-130.

[10] Alexander Vaninsky, Efficiency of electric power generation in the United States: Analysis and forecast based on data envelopment analysis [J], Energy Economics, Energy Economics, 2006(28):326-338.

[11] Coelli T, A multi-stage methodology for the solution of orientated DEA models [J], Operations Research Letters, 1998, 23: 143-149. 